\title{
The surgical stress response and postoperative immune function after laparoscopic or conventional total mesorectal excision in rectal cancer: a randomized trial
}

\author{
A. A. F. A. Veenhof • C. Sietses • B. M. E. von Blomberg • I. M. W. van Hoogstraten • \\ M. H. G. M. vd Pas • W. J. H. J. Meijerink • D. L. vd Peet • M. P. vd Tol • \\ H. J. Bonjer • M. A. Cuesta
}

Accepted: 17 September 2010 / Published online: 5 October 2010

(C) The Author(s) 2010. This article is published with open access at Springerlink.com

\begin{abstract}
Purpose This study evaluated differences in stress response and immunological function following laparoscopic and conventional total mesorectal excision (TME) for rectal cancer.

Methods Patients with non-metastasized rectal cancer were prospectively randomized to open $(n=18)$ or laparoscopic $(n=22)$ TME. Blood samples were taken preoperatively (baseline), 2, 24, and $72 \mathrm{~h}$ following surgery. Systemic white blood cell and monocyte count, C-reactive protein, interleukin-6 (IL-6), interleukin-8 (IL-8), HLA-DR expression on monocytes, growth hormone, prolactin, and cortisol were measured.

Results Forty patients with a median age of 66 years (interquartile range, 60-74 years) were included. Eighteen patients $(45 \%)$ were randomized to open surgery and 22 patients $(55 \%)$ to laparoscopic surgery. Patient demographics in terms of gender, age, BMI, ASA classification, localization of the tumor, and type of neoadjuvant therapy were comparable for both groups. Laparoscopic surgery resulted in a significantly better short-term preservation of postoperative immune function. HLA-DR expression on monocytes was significantly higher $(64 \%$ vs $50 \%, P=$ $0.014)$ and IL-6 level increase was significantly lower (4.6 vs $10.8, P=0.003) 2 \mathrm{~h}$ after laparoscopic surgery. No
\end{abstract}

A. A. F. A. Veenhof $(\bowtie) \cdot$ C. Sietses $\cdot$ M. H. G. M. vd Pas

W. J. H. J. Meijerink · D. L. vd Peet · M. P. vd Tol $\cdot$ H. J. Bonjer

M. A. Cuesta

Department of Surgery, VU University Medical Center,

Post bus 7057, 1007 MB, Amsterdam, The Netherlands

e-mail: a.veenhof@vumc.nl

B. M. E. von Blomberg • I. M. W. van Hoogstraten Department of Pathology, VU University Medical Center, Amsterdam, The Netherlands differences between the open and laparoscopic technique were observed in postoperative white blood cell count, monocyte count, C-reactive protein, IL-8, growth hormone, prolactin, and cortisol levels.

Conclusion Short-term postoperative immune and inflammatory functions tended to be better after laparoscopic rectal surgery. However, the differences were not consistent at all time intervals, making a definitive conclusion difficult. Better preserved inflammatory function $2 \mathrm{~h}$ after surgery may reflect a reduction in operative trauma when the laparoscopic technique is compared with open rectal procedures.

Keywords Immune status · Laparoscopy · Rectal cancer . Total mesorectal excision

\section{Introduction}

Conventional or laparoscopic surgery is a controlled trauma with a stress response and immunological consequences. Operative trauma, measured by the magnitude and type of intra-operative injury determine the extent and duration of the postoperative inflammatory and immunological responses. Postoperative immunesuppression may have important consequences as it has been related to infectious complications and tumor metastasis formation [1-3].

Major surgery remains associated with undesirable postoperative side effects such as pain, cardiopulmonary, infective and thromboembolic complications, gastrointestinal paralysis, fatigue, and prolonged convalescence. A key factor in postoperative morbidity is the surgical stress response with subsequent increased demand on the patient's reserves and immune competence. Increased demands in 
organ functions are thought to be mediated by traumainduced endocrine and metabolic changes. Some laparoscopic interventions have been shown to reduce postoperative morbidity [4-9]. Since the introduction of the laparoscopic approach, immunological competence and stress response to surgery have been increasingly studied in an attempt to explain short-term advantages found for some minimally invasive techniques [10-14]. The most studied cytokine is interleukin-6 (IL-6). It reflects the operative trauma and is a predictor of postoperative complications. Laparoscopic interventions such as Nissen fundoplication [11] and cholecystectomy [14] offer clear clinical advantages in comparison with the conventional approach, probably based on a better preserved immune system. More extensive interventions such as laparoscopic colectomy have also been shown to provide clinical benefits such as a reduction of morbidity, less postoperative pain, earlier recovery, and shorter hospital stay when compared with the open approach [4-8]. As a result, laparoscopic colectomy is increasingly becoming the preferred procedure in clinical practice. At the same time, laparoscopic total mesorectal excision (TME) in rectal cancer is being used more frequently, mostly on trial bases.

Currently, no data is available regarding surgical stress response and immune competence following open or laparoscopic TME surgery in rectal cancer. As a sub-study of the randomized COLOR II study, which compares the open and laparoscopic approach for rectal cancer, we studied the postoperative stress response, inflammatory and immune function in patients undergoing open or laparoscopic TME in an attempt to provide insight into the differences of postoperative trauma here considered.

\section{Study design}

In June 2006, the VU University Medical Center (VUmc) initiated participation in the COLOR II trial; a randomized study comparing laparoscopic to open TME in patients with non-metastasized rectal cancer. All patients who were randomized until December 2008 for the COLOR II trial at the VUmc were included into this sub-study.

The primary endpoints of the study were to demonstrate differences in inflammatory response by evaluating proinflammatory cytokines (interleukin-6 and interleukin-8) and C-reactive protein (CRP); immune status by evaluating white blood cells and HLA-DR expression on monocytes; and stress response by evaluating cortisol, prolactin, and growth hormone in both groups of patients. The protocol was approved by the local ethics committee and informed consent was obtained from all participating patients. Inclusion and exclusion criteria for the present study were as described in the COLOR II protocol (www.color2.org)
In the present study, patients were analyzed according to an intention to treat principle.

\section{Material and methods}

Peripheral blood and serum (BD Vacutainer Systems, Plymouth, UK) were collected preoperatively (baseline), 2,24 , and, $72 \mathrm{~h}$ after surgery.

Serum interleukin-6 and interleukin- 8 samples were obtained by centrifugation for $10 \mathrm{~min}$ at $3,000 \mathrm{rpm}$ at $4^{\circ} \mathrm{C}$. All samples were stored in aliquots at $-80^{\circ} \mathrm{C}$ until tested.

Inflammatory response

\section{Interleukin-6 and interleukin-8}

IL-6 and IL-8 concentrations in serum were measured using commercially available enzyme-linked immunosorbent assay kits (Pelikine compact human ELISA kits, Sanquin, Amsterdam, the Netherlands).

\section{C-reactive protein}

Plasma CRP levels were measured by immunoturbidimetric method, using the BM/Hitachi 705 (Boeingher, Mannheim, Germany).

Immune status

White blood cell count and HLA-DR expression on monocytes

Numbers and phenotype of white blood cells and monocytes were determined in fresh $(<2 \mathrm{~h})$ heparinized venous blood. Phenotyping was performed by using CD14-PE and HLA-DR-FITC moAbs (Becton Dickinson), subsequent lysis of erythrocytes, and fixation with paraformaldyde. Monocyte HLA-DR expression was evaluated by FACS analysis (FACS Calibur, Becton Dickinson, San Jose, CA, USA) quantified by using calibration beads (QuantumTM 26, Flow Cytometry Standards Corp, Bangs Laboratories, Inc, Fishers, IN) and expressed as ratio of the mean fluorescence intensity post/pre surgery.

Stress response

Cortisol

Cortisol concentrations in serum were measured by competitive immunoassay (Bayer Diagnostics, Mijdrecht, The Netherlands) 


\section{Prolactin}

Prolactin concentrations in serum were measured by immunometric assay (DPC, Los Angeles, USA)

\section{Growth hormone}

Growth hormone concentrations in serum were measured by immunometric Assay (Bayer Diagnostics, Mijdrecht, The Netherlands)

\section{Statistical analysis}

Statistical analysis was performed using the SPSS software package (SPSS 16.0 for Windows; SPSS, Chicago, IL, USA). Medians, means, ranges, and interquartile ranges were calculated and subsequently depicted when appropriate. The Mann-Whitney $U$ test, Chi-squared test, or Fisher's exact test were applied when appropriate for group comparisons. The independent samples $T$ test was used to compare group means. Significance was set at $p<0.05$

\section{Results}

Forty patients with a median age of 66 years (interquartile range, 60-74 years) were included in this prospective randomized trial. Twenty-eight men (70\%) and 12 women $(30 \%)$ with a median body mass index of $25 \mathrm{~kg} / \mathrm{m}^{2}$ (interquartile range: $23.5-26.4 \mathrm{~kg} / \mathrm{m}^{2}$ ). Median distance of the tumor to the anal verge was $10 \mathrm{~cm}$ (interquartile range: $5.5-15 \mathrm{~cm})$. Eighteen patients $(45 \%)$ were randomized to open surgery and 22 patients (55\%) to laparoscopic surgery.

The demographic data are shown in Table 1. Patient characteristics in terms of gender, age, body mass index, ASA classification, localization of the tumor, and type of neoadjuvant therapy were comparable for the open and laparoscopic groups (Table 1). Furthermore, type of operation, proximal mesorectal excision, TME, or abdominoperineal resection was comparable. Operation time was significantly longer for laparoscopic procedures, but was accompanied by less blood loss. In patients randomized to laparoscopic surgery, two patients needed some form of conversion by a Pfannenstiel incision and were analyzed according to an intention to treat principle.

Morbidity and mortality data, for both groups, are depicted in Table 2. In the laparoscopic and in the open group, six (27\%) and four (22\%) patients had some form of (infectious) complications $(P=0.71)$, respectively. The median time to develop the complication in the laparoscopic and open group was 5 days (range 1-10 days) and 6 days (range 3-7 days), respectively. No mortality was seen in the laparoscopic group, one patient died 3 days postoperatively in the open group due to myocardial infarction $(P=0.45)$. No differences were observed in terms of tumor stage or extensity of resection (expressed by lymph node harvest and specimen length).

\section{Inflammatory response}

Interleukin-6 levels were comparable for both groups at baseline $(P=0.201)$. Levels showed a significantly lower increase $2 \mathrm{~h}$ following laparoscopic surgery when compared to the open approach (4.6 vs. $10.8, P=0.003$ ). No differences were detected 24 and $72 \mathrm{~h}$ following surgery (Fig. 1). No significant differences between the laparoscopic or open approach in the increase of C-reactive protein level and IL8 levels were detected. (Table 3 )

Immune status

Monocyte HLA-DR expression was used as a parameter for surgery-induced immune competence. HLA-DR expression was comparable at baseline $(P=0.251)$. Two hours following open surgery, an HLA-DR expression on monocytes was significantly better preserved in the laparoscopic approach $(64 \%$ vs. $50 \%, P=0.014)$. After 24 and $72 \mathrm{~h}$, the values did not show any significant difference between both groups (Fig. 2). No significant differences between the laparoscopic or open approach in postoperative white blood cell or monocyte count were detected. (Table 3)

\section{Stress response}

Growth hormone, cortisol, and prolactin levels were used to indicate the postoperative stress response. No significant differences between both groups were found in postoperative stress response levels. (Table 3)

\section{Discussion}

In general, laparoscopic surgery is thought to reduce the magnitude of operative trauma. If alterations of immune function and stress response are proportional to the extent of injury, the response following laparoscopic surgery will be reduced when compared with conventional surgery. Many studies have shown that relatively wound-limited interventions such as laparoscopic Nissen fundoplication [11] and cholecystectomy [14] are associated with a tempered systemic inflammatory response and preservation of the postoperative immune function when compared to the open approach. The stress response to injury and surgery has also been previously described. Anterior pituitary hormone secretion is stimulated by hypothalamic 
Table 1 Patient and tumor characteristics

\begin{tabular}{|c|c|c|c|}
\hline Variable & Laparoscoopic TME $(n=22)$ & Open TME $(n=18)$ & Significance \\
\hline Gender; no. (\%) & & & $P=0.68$ \\
\hline Male & $16(73 \%)$ & $12(67 \%)$ & \\
\hline Female & $6(27 \%)$ & $6(33 \%)$ & \\
\hline Age (years); median (interquartile range) & $64(59-74)$ & $67(61-74)$ & $P=0.74$ \\
\hline Body mass index $\left(\mathrm{kg} / \mathrm{m}^{2}\right)$; median, (interquartile range) & $24(23-26)$ & $25(24-26)$ & $P=0.012$ \\
\hline \multicolumn{4}{|l|}{ ASA classification } \\
\hline 1 & $7(32 \%)$ & $5(28 \%)$ & \\
\hline 2 & $10(45 \%)$ & $10(56 \%)$ & \\
\hline 3 & $5(23 \%)$ & $3(16 \%)$ & \\
\hline \multicolumn{4}{|l|}{ Tumor localization } \\
\hline Median distance from anal verge; cm (full range) & $11(6-15)$ & $9(5-12)$ & $P=0.26$ \\
\hline Neoadjuvant therapy; no. (\%) & & & $P=0.69$ \\
\hline 5 Fractions of 5 Gy & $8(36 \%)$ & $7(39 \%)$ & \\
\hline 28 Fractions of $1.8 \mathrm{~Gy}$ & $2(9 \%)$ & $3(17 \%)$ & \\
\hline \multicolumn{4}{|l|}{ Operation } \\
\hline Anterior resection & $18(82 \%)$ & $13(7 \%)$ & $P=0.71$ \\
\hline Abdominoperineal resection & $4(18 \%)$ & $5(28 \%)$ & \\
\hline Proximal mesorecatal excision (PME) & $11(61 \%)$ & $9(69 \%)$ & $P=0.87$ \\
\hline Total mesorectal excision (TME) & $7(39 \%)$ & $4(44 \%)$ & \\
\hline Operation time (min); median (range) & $206(135-305)$ & $159(100-205)$ & $P=0.001$ \\
\hline Blood loss (ml); median (range) & $127(20-350)$ & $328(100-800)$ & $P<0.001$ \\
\hline
\end{tabular}

Table 2 Postoperative data and complication within 30 days

\begin{tabular}{|c|c|c|c|}
\hline Variable & Laparoscoopic TME $(n=22)$ & Open TME $(n=18)$ & Significance \\
\hline Hospital stay; median (interquartile range) & 9 days $(5-15)$ & 8 days $(7-10)$ & $P=0.19$ \\
\hline Mortality & - & $1(6 \%)$ & $P=0.45$ \\
\hline Complications per patient; no. (\%) & $6(27 \%)$ & $4(22 \%)$ & $P=0.71$ \\
\hline Anastomosis leak & $3(16 \%)$ & $1(9 \%)$ & \\
\hline Pelvic abscess & $1(5 \%)$ & - & \\
\hline Pneumonia & - & $2(11 \%)$ & \\
\hline Cardiac complaints & - & - & \\
\hline Ileus & $1(5 \%)$ & - & \\
\hline Wound infection & $1(5 \%)$ & $1(6 \%)$ & \\
\hline Tumor stage & & & $P=0.17$ \\
\hline Astler-Coller A & 5 & 2 & \\
\hline Astler-Coller B1 & 6 & 3 & \\
\hline Astler-Coller B2 & 5 & 7 & \\
\hline Astler-Coller C1 & 2 & 1 & \\
\hline Astler-Coller C2 & 3 & 3 & \\
\hline Astler-Coller X & 1 & 2 & \\
\hline Lymph node resection; median (range) & $10(3-23)$ & $9(3-24)$ & $P=0.32$ \\
\hline Length resection specimen $(\mathrm{cm})$; median range & $25(12-48)$ & $19(15-46)$ & $P=0.62$ \\
\hline
\end{tabular}

Astler-Coller X: complete remission after neoadjuvant therapy 


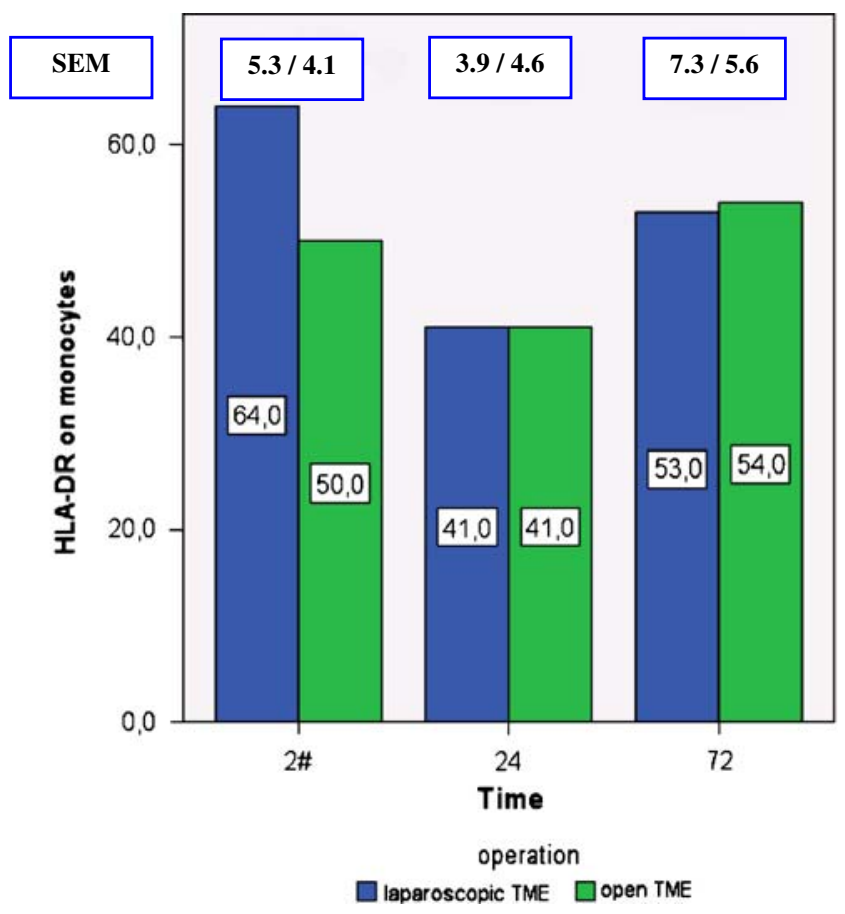

Fig. 1 HLA-DR on monocytes in percentage compared to preoperative. ( $\#, P=0.014$ )

releasing factors $[15,16]$. Cortisol, growth hormone, and prolactin are secreted in increased amounts from the pituitary in response to a surgical stimulus. Currently, there are few data of postoperative immune function and stress response after more invasive procedure such as laparoscopic colectomy and rectal resections.

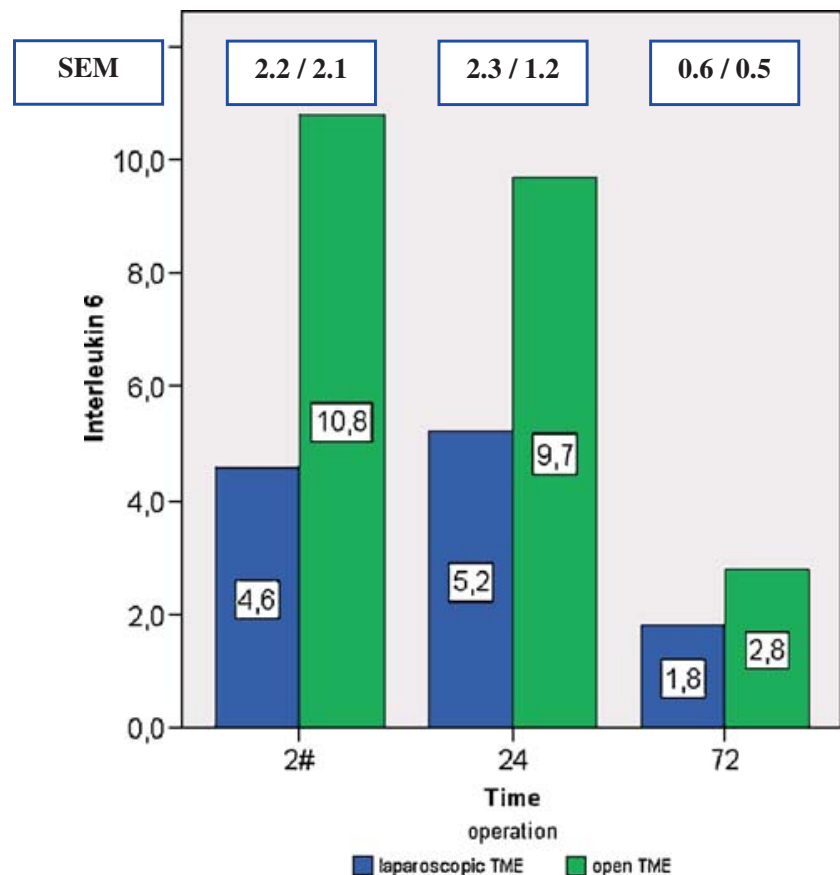

Fig. 2 Interleukin-6 expression in fold increase compared to preoperative. (\#, $P=0.003$ )

In more extensive operations, with more operative wound surface such as laparoscopic colectomy, differences with the conventional approach concerning systemic inflammatory and immune response are more difficult to demonstrate and only a relatively low postoperative IL-6 level has been found consistently in the laparoscopic group.
Table 3 Postoperative immune and stress response

Values are depicted as foldincrease values with the preoperative value set at $100 \%$

${ }^{a}$ Significant difference

\begin{tabular}{llccr}
\hline Variable & Groups & $2 \mathrm{~h}$ & $24 \mathrm{~h}$ & $72 \mathrm{~h}$ \\
\hline Leucocyte count & Lap & $1.6(0.7-2.9)$ & $1.9(0.9-2.7)$ & $1.5(0.9-2.8)$ \\
& Open & $1.7(1.0-3.5)$ & $1.8(0.9-3.6)$ & $1.7(1.0-3.2)$ \\
Monocyte count & Lap & $0.8(0.4-1.1)$ & $1.0(0.6-1.6)$ & $0.9(0.5-1.9)$ \\
& Open & $0.8(0.5-1.2)$ & $0.9(0.5-1.6)$ & $1.0(0.4-1.5)$ \\
C-reactive protein & Lap & $7.3(0.6-45)$ & $36(1.5-78)$ & $56(9.6-144)$ \\
& Open & $4.0(0.7-55)$ & $39(1.8-65)$ & $47(14-105)$ \\
HLA-DR & Lap & $0.64(0.31-1.06)^{\mathrm{a}}$ & $0.41(0.12-0.73)$ & $0.53(0.15-1.39)$ \\
IL-6 & Open & $0.50(0.32-0.94)^{\mathrm{a}}$ & $0.41(0.22-0.84)$ & $0.54(0.21-1.17)$ \\
IL-8 & Lap & $4.6(0.3-35.8)^{\mathrm{a}}$ & $5.2(0.3-17.6)$ & $1.8(0.4-7.5)$ \\
Growth hormone & $10.8(0.2-27.0)^{\mathrm{a}}$ & $9.7(1.6-38.9)$ & $2.8(0.3-8.9)$ \\
& Open & $2.0(0.4-7.1)$ & $1.7(0.5-8.1)$ & $1.6(0.4-7.4)$ \\
Prolactin & Lap & $2.4(0.8-6.1)$ & $1.3(0.2-2.6)$ & $1.6(0.4-6.1)$ \\
& Open & $2.6(0.03-1.5)$ & $7.6(0.03-6.6)$ & $2.9(0.02-1.6)$ \\
Cortisol & Open & $9.4(0.01-3.6)$ & $6.7(0.05-2.8)$ & $3.9(0.02-1.3)$ \\
& Lap & $3.0(0.13-12)$ & $0.7(0.04-2)$ & $0.7(0.04-1.9)$ \\
& Open & $5.6(0.3-11)$ & $1.2(0.13-7.1)$ & $1.1(0.9-3.1)$ \\
& Lap & $1.2(0.2-2.2)$ & $1.3(0.2-3.8)$ & $1.3(0.6-3.8)$ \\
& Open & $1.3(0.1-3.4)$ & $1.2(0.4-2.7)$ & $1.9(0.3-12)$ \\
\hline
\end{tabular}


Harmon et al. [17] were the first to describe differences in postoperative IL-6 levels when laparoscopic colectomy was compared to the open technique. Wu et al. [10] measured cytokine levels both in serum as well as in peritoneal drain fluid. They found significantly lower levels of IL-6 after laparoscopic surgery confirming the earlier studies. CRP is the only acute phase protein which was measured. Since IL6 is the mean stimulator of CRP production, it is not surprising that the results are comparable. A large randomized study by Schwenk et al. [13] showed significantly lower peak concentrations of IL- 6 and CRP 2 days after colon surgery. Nevertheless, short-term clinical advantages of laparoscopic colectomy have been shown in different randomized studies. This has been the reason to extend the laparoscopic approach to the surgical treatment of rectal cancer by means of laparoscopic TME, mostly on trial bases.

To demonstrate clinical differences between open and laparoscopic TME, especially the rate of local recurrence and morbidity, the COLOR II study was started. Along with these questions, the study of biological consequences will offer more insight in the possible advantages of these two different surgical approaches to rectal cancer.

In the here presented sub-study of the randomized COLOR II trial, the immune competence and stress response following laparoscopic and open TME has demonstrated some subtle differences between both groups. Significantly lower levels of IL-6 were detected $2 \mathrm{~h}$ following laparoscopic surgery; in the subsequent days this difference diminished in concordance with a previous study presented by our institution regarding open and laparoscopic colectomy [10]. Moreover, a significant lower depression was found in immune competence $2 \mathrm{~h}$ following laparoscopic surgery, since HLA-DR expression was better preserved. This may be interpreted as an important shortterm enhanced defense mechanism after laparoscopy, against infections but also theoretically against spreading malignant cells in the circulation [2]. Wind et al. [18] described an important increase in circulating tumor cells shortly after initiating surgery. Therefore, a better preserved immune function could prevent tumor nestling and therefore distant metastases formation. Therefore, it will be interesting to further investigate if the short-term advantages described in the present study will have oncological advantages in the long-term. However, in the subsequent days the differences diminished, as described for the IL-6 levels. No significant differences between open and laparoscopic surgery were found regarding white blood cell count, monocyte count, C-reactive protein level, interleukin-8 level, or cortisol level. Moreover, no differences could be found regarding postoperative stress response.

In conclusion, although after both laparoscopic and open TME a decrease in immune competence is seen, this competence is better preserved immediately after laparoscopic surgery when compared to the open approach. Also, IL-6 levels are lower $2 \mathrm{~h}$ following laparoscopic surgery, indicating a diminished surgical trauma. However, the differences were not consistent at all time intervals, making a definitive conclusion difficult. Although, in the present study, the described differences did not result in any clinical advantages such as less morbidity, the differences on the short term may reflect the less-invasive character of the laparoscopic TME procedure when compared to the open approach. Moreover, an increased immune response may be most important shortly after initiating surgery as the level of circulating tumor cells is highest following manipulation of the tumor [18]. Larger studies are required for more definitive results.

Open Access This article is distributed under the terms of the Creative Commons Attribution Noncommercial License which permits any noncommercial use, distribution, and reproduction in any medium, provided the original author(s) and source are credited.

\section{References}

1. Lennard TW, Shenton BK, Borzotta A, Donnelly PK, White M, Gerrie LM, Proud G, Tayler RM (1885) The influence of surgical operations on components of the immune system. Br J Surg 72:771-776

2. Allendorf JD, Bessler M, Horvath KD, Marvin MR, Laird DA, Whelan RL (1999) Increased tumor establishment and growth after open vs laparoscopic surgery in mice may be related to differences in postoperative T-cell function. Surg Endosc 13:233235

3. Wakefield CH, Carey PD, Foulds S, Monson JR, Guillou PJ (1993) Changes in major histocompatibility complex class II expression in monocytes and T-cells of patients developing infection after surgery. Br J Surg 80:205-209

4. Jacobs M, Verdeja JC, Goldstein HS (1991) Minimally invasive colon resection (laparoscopic colectomy). Surg Laparosc Endosc $1: 144-150$

5. Lacy AM, García-Valdecasas JC, Delgado S, Castells A, Taurá P, Piqué JM, Visa J (2002) Laparoscopy-assisted colectomy versus open colectomy for treatment of non-metastatic colon cancer: a randomised trial. Lancet 359:2224-2229

6. Nelson H, Sargent DJ, Wieand S, Fleshman J, Anvari M, Stryker SJ, Beart RW, Hellinger M, Flanagan R, Peters W, Ota D (2004) A comparison of laparoscopically assisted and open colectomy for colon cancer. N Engl J Med 350:2050-2059

7. The Colon cancer Laparoscopic or Open Resection Study Group (2005) Laparoscopic surgery versus open surgery for colon cancer: short-term outcomes of a randomised trial. Lancet Oncol 6:477-484

8. Basse L, Jakobsen DH, Billesbolle P, Werner M, Kehlet H (2000) A clinical pathway to accelerated recovery after colonic resection. Ann Surg 232:51-57

9. Guillou PJ, Quirke P, Thorpe H, Walker J, Jayne DG, Smith AM, Heath RM (2005) Short-term endpoints of conventional versus laparoscopic-assisted surgery in patients with colorectal cancer (MRC CLASICC trial): multicentre, randomised controlled trial. Lancet 365:1718-1726

10. Wu FPK, Sietses C, von Blomberg BME, van Leeuwen PAM, Meijer S, Cuesta MA (2003) Systemic and peritoneal inflamma- 
tory response after laparoscopic or conventional colon resection in cancer patients: a prospective, randomized trial. Dis Colon Rectum 46:147-155

11. Sietses C, Wiezer MJ, Eijsbouts QAJ, Beelen RHJ, van Leeuwen PAM, von Blomberg BME, Meijer S, Cuesta MA (1999) A prospective randomized study of the systemic immune response after laparoscopic and conventional Nissen fundoplication. Surgery 126:5-9

12. Ordemann J, Jacobi CA, Schwenk W, Stosslein R, Muller JM (2001) Cellular and humoral inflammatory response after laparoscopic and conventional colorectal resections. Surg Endosc 15:600-608

13. Schwenk W, Jacobi C, Mansmann U, Bohm B, Muller JM (2000) Inflammatory response after laparoscopic and conventional colorectal resections - results of a prospective randomized trial. Langenbeck's Arch Surg 385:2-9
14. Targorona EM, Pons MJ, Balague C, Espert JJ, Moral A, Martinez J, Gaya J, Filella X, Rivera F, Ballesta A, Trias M (1996) Acute phase is the only significantly reduced component of the injury response after laparoscopic cholecystectomy. World J Surg 20:528-534

15. Lyons FM, Meeran K (1997) The physiology of the endocrine system. Int Anesthesiol Clin 35:1-21

16. Desborough JP (2000) The stress response to trauma and surgery. Br J Anaesth 85:109-117

17. Harmon GD, Senagore AJ, Kilbride MJ, Warzynski MJ (1994) Interleukin-6 response to laparoscopic and open colectomy. Dis Colon Rectum 37:754-759

18. Wind J, Tuynman JB, Tibbe AGJ, Swennenhuis JF, Richel DJ, van Berge Henegouwen MI, Bemelman WA (2009) Circulating tumour cells during laparoscopic and open surgery for primary colonic cancer in portal and peripheral blood. EJSO 35:942-950 